\title{
Quadriplegia following Tracheoplasty
}

Perera M. B., Jayasuriya C., Rupasinghe S., Jayalath J. M. S.

National Hospital of Sri Lanka.

\begin{abstract}
We report a case of a 19-year-old female who with tracheal stenosis following prolonged intubation due to organophosphorous poisoning. Crico tracheal resection and end to end laryngotracheal anastomosis was done. She developed quadriplegia on the $2^{\text {nd }}$ post-operative day. MRI revealed ischemic segment from C3 to $\mathrm{T} 1$ segments of spinal cord. We think that the decreased blood flow in the anterior spinal artery with flexion of the neck in combination with hypotension was the direct cause of this major complication. Quadriplegia is a rare complication following Tracheoplasty and should be considered included in the routine consent.
\end{abstract}

\section{Case Report}

In May 2014, a 19year old female was admitted to our hospital with a tracheal stenosis caused by an intentional organophosphorus poisoning in 2013, where she was intubated and had prolonged ventilation at a local hospital. A tracheostomy was done on the $28^{\text {th }}$ post-operative day and she was de cannulated 3 days after. She developed stridor 4 days after decanulation which warranted a repeat tracheostomy at the local hospital as an endotracheal tube could not be passed due to tracheal stenosis above the level of tracheostomy.

Further evaluation at our unit was done and a CT scan of the neck revealed, a long segment narrowing of the trachea from C6 vertebral level up to the tracheostomy site. Fiber optic bronchoscopy revealed a grade 4 tracheal stenosis beneath a normal glottis. Routine preoperative investigations were normal and a tracheal resection planned.

During surgery, a sub glottic $4 \mathrm{~cm}$ long stenotic tracheal segment was identified and tracheal resection with cricotracheal end to end anastomosis was performed. Valsalva maneuver was performed to confirm patency of anastomosis. Relatively less tension was noted over the suture line and routine closure was done. A nasotracheal tube was kept insitu to aid in ventilation and the chin sutured to sternum to prevent undue extension. Post-operative ICU care was given which was uneventful, except one episode of unexplained hypotension, which was corrected with administration of crystalloids.

On the $2^{\text {nd }}$ post-operative day, the patient complained of numbness of both lower limbs. We incidentally noted quadriplegia with a motor level up to the $7^{\text {th }}$ cervical and sensory level up to the $4^{\text {th }}$ cervical spinal cord segment. An urgent MRI and MRA of the spinal cord and cervical vertebrae were done. MRI revealed and ischemic segment of the spinal cord partially extending from C3 to T1 spinal cord segments. MRA revealed no abnormality. Her pre-operative and post-operative coagulation studies did not reveal any coagulopathy. She subsequently developed diaphragmatic breathing for which ICU care with ventilation with minimal support was given. She ultimately developed type 1 respiratory failure with concomitant sepsis and died one month after surgery.

\section{Discussion}

Tracheal resection is performed in adults and paediatric age groups with indications ranging from inflammatory, neoplastic, to congenital causes. Bleeding, infection, airway oedema, pulmonary insufficiency, anastomotic dehiscence, anastomotic fistula, tumour recurrence, anastomotic stenosis, anastomotic leak are all well documented complications in literature ${ }^{4,5}$. In neurosurgical and cardiothoracic procedures, quadriplegia is a well-known complication ${ }^{6}$. Especially in aortic reconstruction with prolonged cross clamping of the aorta or division of one or 
more intercostal arteries at the level of the lower thoracic vertebra, the blood supply of the spinal medulla in compromised.

Quadriplegia is a very rare complication where only 3 case reports are available on a pub med search $^{1,2,3}$. We believe this complication may have occurred due to an anterior spinal artery or vertebral artery insufficiency with associated hypotension immediate post op. Doppler studies were not available to confirm our assumption. But considering the anatomical details of the arterial supply of the cervical spinal cord, we assumed the anterior spinal artery or vertebral artery insufficiency occurred following flexion of the neck aggravated with hypotension. Similar assumption had been made in a previous reported case $^{1}$. Obstruction of the anterior spinal artery occurs in several diseases, i.e., embolization during or following aortic surgery, arteritides, aortic dissections, cervical spondylosis, cervical intervertebral disk hernia, syphilis, and compression by tumor ${ }^{6}$. In general, occlusion of the anterior artery leads to a loss of pain and temperature sensation below the level of the lesion in combination with a paralysis of motor function and a relative or absolute sparing of the proprioceptive sensation.

The prognosis depends on the duration of occlusion and the existence of anastomosis. Literature revealed one report where the chin to sternum suture was removed immediately post op when quadriplegia was noted, where the patient recovered $^{3}$. A delayed detection in our subject meant limited value of treating the patient with steroids to decrease cord oedema, while partial ischemia of the cervical spinal segments spared the left diaphragmatic breathing, which was compromised by superadded respiratory tract infection, which eventually led to respiratory failure and death.

\section{Key Messages.}

1. We recommend taking detailed consent including the possibility of quadriplegia in all patients undergoing Tracheoplasty.

2. Post op neurological examination following immediate recovery should be performed in these patients along with daily routine neurologic examinations.

\section{References.}

1. Jochen, P.W., Alexander Dülks, Spinal cord infarction following cricotracheal resection

2. Silver, J.R., Paraplegia as a result of tracheal resection in a 17-year-old male, PMID: 17091121

3. Pitz, C.C., Duurkens, V.A., Goossens, D.J., Knaepen, P.J., Siegers, P., Hoogenboom, L.J., Tetraplegia after a tracheal resection procedure.

\section{Dale K Mueller, Zab Mosenifar, Tracheal Resection, Medscape}

5. Michael J Rutrer, Ai'jd Robin T Cotton, Scott Brown's otorhinolaryngology, head and neck surgery , $7^{\text {th }}$ Edition pg. 1155-1166

6. Frank W. Sellke, Pedro J. del Nido, Scott J. Swanson, Sabiston and Spencers surgery of the chest 8th edition 